\title{
Creatividad en pista I: Visualización sentida
}

\author{
Lucía Jiménez
}

\section{Feel in flow}

\section{RESUMEN}

En este artículo se presentan dos ejemplos de práctica imaginada, poniéndose énfasis en las sensaciones que acompañan a las visualizaciones (calidad de la imagen, sonidos o emociones) como forma de aumentar la eficacia de esta herramienta. Se aportan además sugerencias prácticas sobre su aplicación.
Palabras clave: : Práctica imaginada, visualización, sensaciones, ejercicios

Recibido: 08 Jul 2017

Aceptado: 20 Oct 2017

Autor correspondiente: Lucía Jiménez, Feel in flow. Correo electrónico: lucia@feelinflow.com

\section{INTRODUCCIÓN}

"Solo la imaginación es más poderosa que el conocimiento" (Albert Einstein)

"I believe in the power of the mind and visualization, which is a big part of my everyday life." (Novak Djokovic)

La práctica imaginada, más comúnmente conocida como visualización, hace referencia al uso de los sentidos para recrear o crear una experiencia en la mente (Vealey y Greenleaf, 2001). Es un recurso que, si bien ha sido reconocido en el contexto deportivo desde hace mucho tiempo (ver Cox, 2009), no se ha hecho un uso sistemático proporcional a este reconocimiento.

El poder de la práctica imaginada es enorme puesto que tiene la capacidad de reproducir, a nivel cerebral, rutas neurológicas que se recorren si llevásemos a cabo la situación en la realidad (Fisher, 1986). Entre los beneficios descritos, se sugiere que la práctica imaginada puede mejorar aspectos tales como la confianza, el proceso de aprendizaje, disminuir los errores, reducir la ansiedad o facilitar la rehabilitación de lesiones (Crespo, Reid y Quinn, 2006), así como facilitar la mejora de la técnica (Guillot, Desliens, Rouyer, \& Rogowski, 2013).

La propuesta para este artículo consiste en dotar la imagen de todos los sentidos, poniendo especial énfasis en las sensaciones físicas, en la calidad de los sonidos, y sobre todo... en las emociones; en definitiva, realizar una visualización sentida, conectando con la emoción tal y como se sentirá una vez logrado el objetivo propuesto. Experimentar la emoción proporcionará mucha más credibilidad para nuestro cerebro, con lo que su materialización en el plano real se verá impulsada de manera más intensa a través del plano virtual.

\section{CONSIDERACIONES PRÁCTICAS}

\section{¿Puede cualquier jugador visualizar?}

Quien haya competido sabe lo que significa pasar una noche sin dormir imaginando escenarios posibles relacionados con el partido del día siguiente, con el torneo... ¿No le ha pasado nunca imaginar a su oponente pegando golpes de una precisión extrema, con una potencia irreconocible y de una elegancia sobrenatural...? Esta es la mejor prueba de que todos visualizamos, la clave reside en hacerlo de forma voluntaria, consciente y orientada a nuestros objetivos, y evitar así hacerlo de manera inconsciente y reactiva, fruto de la tensión.

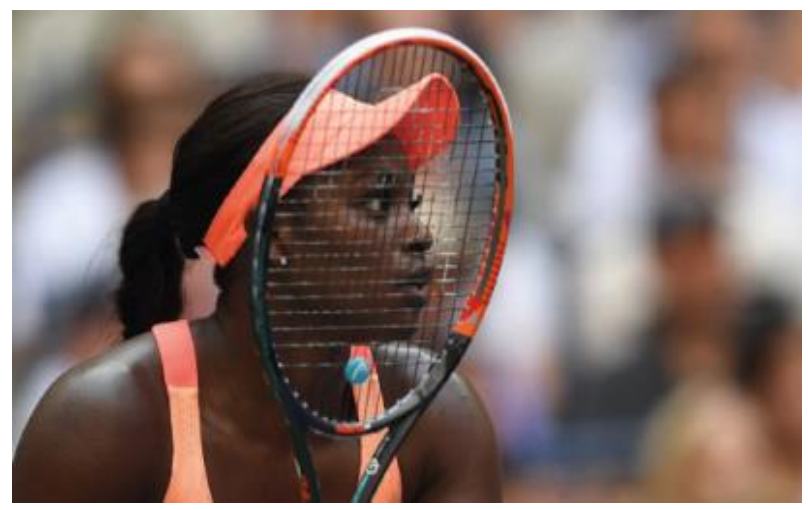

Uno de los aspectos determinantes a tener en cuenta para aumentar su efectividad, son los canales de percepción preferentes, es decir, la facilidad del jugador para "ver", para 
"oír" o para "sentir". En cualquier caso y más allá de este canal de percepción, todos, con entrenamiento, se pueden desarrollar.

\section{¿Cómo empezar?}

Dado que tendemos a recordar con más facilidad situaciones similares a las de nuestro estado emocional (FernándezAbascal, Jiménez Sánchez, Martín Díaz, \& Domínguez Sánchez, 2010), conviene asegurarnos de que nuestro jugador se encuentra en un estado de ánimo óptimo, de confianza y satisfacción. De esta forma estaremos facilitando que conecte con otros momentos de confianza y logro en los que realizó cambios similares.

\section{Pautas básicas}

En relación al contenido: Si lo que se pretende es incorporar un nuevo gesto técnico, una posibilidad consiste en conectar con las sensaciones y con la proyección de la imagen directamente. Si lo que se pretende es inducir un estado, se recomienda realizar un calentamiento visual (e.g. respiraciones), una parte principal (e.g. la técnica) y un final.

En relación a la velocidad y duración. Dependerá del objetivo y del entorno. Si estamos en pleno ejercicio en pista, convendrá realizar una práctica imaginada directa y rápida, imaginando el gesto técnico o induciendo el estado deseado de acuerdo al objetivo y a las características de nuestro jugador. Si, por contra, estamos en el comienzo del cambio/aprendizaje, conviene tomarse tiempo suficiente para que el cerebro integre las nuevas modificaciones, recreándose en el movimiento y especialmente en las sensaciones.

¿En movimiento? ¿Con o sin raqueta? El acompañamiento del golpe con raqueta resulta especialmente recomendable en jugadores de nivel intermedio, con cierto manejo de la técnica, no siendo tan determinante en jugadores de mayor nivel (Mizuguchi, Takahiro, Nakata, \& Kanosue, 2015). Nuestra sugerencia es probar y que sea el jugador el que determine la manera más efectiva.

\section{EJERCICIOS}

Los siguientes ejemplos de práctica imaginada tienen el fin de que, como entrenador, puedas hacer uso de los mismos en función de las necesidades y situación global del jugador. Es fundamental probarlas en uno mismo antes de realizarla con otros, así te familiarizarás con las sensaciones, con los tiempos, con el tono de voz... en definitiva, tendrás una mayor capacidad para conectar con tus emociones, así como con las de tu jugador.

\section{Captar la sensación del golpe}

$1^{\circ}$.Realiza una serie de 15 golpes en pista. Simplemente observa y sé consciente de tus sensaciones.

$2^{\circ}$.Al finalizar, para, cierra un momento los ojos y pon tu atención en las sensaciones corporales.

$3^{\circ}$.Permite, por un momento, que el propio golpe te dé la información necesaria (punto de impacto, timing, touch, peso del cuerpo, actitud corporal, intensidad, sonido, posición de la mano libre, contracción del tronco...). Date permiso para que el propio golpe te diga lo que necesita. Puedes preguntarte: para ser más fluido/directo/natural/fuerte/firme, ¿qué está necesitando? Tómate un minuto para captarlo.

$4^{\circ}$.Ahora, observa internamente y siente el golpe tal y como consideras que habría de ser: primero las sensaciones, después la firmeza, la fluidez; siendo consciente también del peso del cuerpo en un pie, en otro... e incluso observando cómo sale la bola de tu raqueta, la dirección...

$5^{\circ}$.Por último, sin necesidad de pensar o verbalizar, termina el ejercicio siendo consciente de cómo tu cuerpo integra ahora, y más adelante, las modificaciones que ha considerado más convenientes.

\section{Sugerencias:}

- Duración y lugar: 3-5minutos, en pista.

- La clave reside en no juzgar el gesto como “bien/mal”, sino en la pura observación de lo que sucede.

- Con práctica y constancia, la observación se convertirá en algo natural y posibilitará las modificaciones y el aprendizaje.

- Ejercicio inspirado en la propuesta de Gallwey (1997)

Tabla 1. Sugerencias para el ejercicio 1.

\section{Intensificar un estado: Determinación}

"Dudo, no presumo de ser una persona segura de sí misma... pero mi cabeza me ha permitido jugar con determinación en los momentos importantes, de presión" (Rafael Nadal)

$1^{\circ}$.Trae a tu memoria una situación en la que experimentaste una gran valentía jugando... valentía y convicción, con acierto.

$2^{\circ}$. Obsérvate: tus hombros, la cabeza alta, mirada adelante, el paso seguro... siente tus movimientos... la intensidad de 
tus piernas y tu corazón, ligeros, fuertes. Date cuenta también de la respiración intensa y centrada que te carga de energía a cada inspiración... y descarga lo innecesario en cada espiración... Permite que esa inspiración dé lugar al golpe preciso en cada instante (...)

$3^{\circ}$. Acerca por un momento la imagen mental, como si tuvieses un zoom y pudieses modificarlo a tu antojo. Acércala un poquito más... eso es... muy bien... Ahora hazla algo más grande. Observa cuál es el punto en el que la imagen adquiere más intensidad

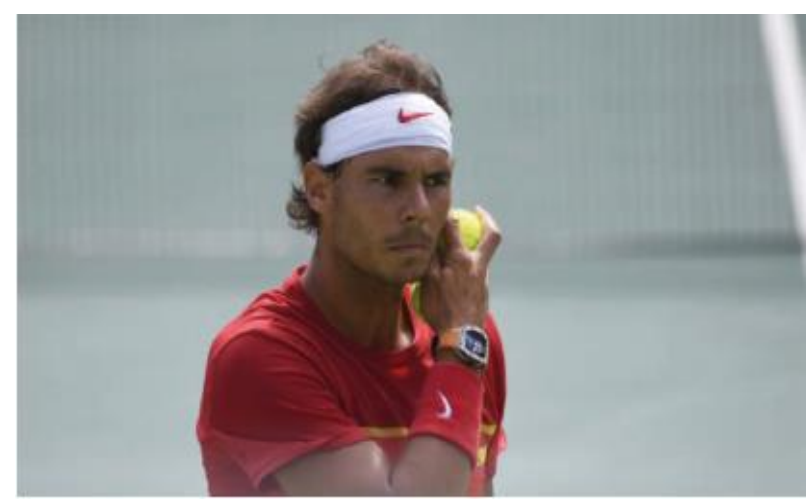

y mejores sensaciones para ti (...) fíjalo... Haz lo mismo con la claridad de la imagen: intensifica (o disminuye) por momentos el color, el brillo, la nitidez... estableciendo una imagen con la que te sientas totalmente a gusto, decidido.

$4^{\circ}$. Pasa ahora a los sonidos, escucha el impacto perfecto de la bola en tu raqueta... sé consciente también del sonido que haces cuando golpeas, el sonido que hace el jugador con quien estás jugando... los sonidos de fuera... Aumenta (o reduce) el volumen de los elementos que tú quieras, tal vez puedas hacer que se oiga más profundo, fuerte, decidido... Ajústalo... así es... a tu propia manera... hasta que sea perfecto para ti.

\section{Sugerencias:}

- Duración y lugar: 5-7minutos, en pista.

- A medida que el jugador se familiarice con la misma, el tiempo tiende a reducirse.

- Una vez establecido el anclaje (gesto, palabra...) repetirlo de manera constante en cada entrenamiento. Cuanto más se repita, mayor efectividad y más rápido conectará el jugador con la sensación inducida. En varias semanas bastará con activar el anclaje (hacer el gesto, repetir la palabra o frase) para conectar con las sensaciones.

Tabla 2. Sugerencias para el ejercicio II. $5^{\circ}$. Siente ahora cuál es el gesto que haces que te conecta con la valentía y determinación que estás sintiendo en este momento, (si no tienes ninguno, puedes aprovechar este momento para realizarlo). Eso es... Sé consciente ahora de lo que te dices, ¿alguna palabra o frase que capte la sensación...?

$6^{\circ}$. Permanece en ese estado por unos momentos... (1-2min).

$7^{\circ}$. Cuando estés preparado, vuelve de nuevo a esta pista y abre los ojos.

\section{LA OTRA CARA DE LA PRÁCTICA IMAGINADA}

En ocasiones la práctica imaginada puede volverse contraproducente. La pérdida de confianza de un jugador trae consigo diversas consecuencias que afectan inevitablemente a la efectividad de las estrategias de mejora implementadas. Cuando un jugador es presa de un estado de ánimo limitante encuentra, frecuentemente, dificultades para conectar con la situación o el estado deseado, se ve incapaz de revivirlo o imaginarlo, produciéndose una sensación de frustración totalmente opuesta al interés pretendido. En situaciones así lo recomendable es, o bien guiar al jugador para modificar la emoción (mediante charla, relajación, evocando un recuerdo, etc.) y realizar la práctica, o bien descartar el ejercicio temporalmente.

\section{CONCLUSIÓN}

La única manera de comprobar el alcance de los beneficios de la práctica imaginada es a través de su aplicación. La sugerencia es que practiques de manera consciente y orientada a los objetivos; las mejoras no tardarán en llegar y estarás, además, mejorando complementariamente aspectos fundamentales para el rendimiento, tales como la capacidad de concentración, la regulación emocional o el control de los pensamientos. En la Tabla 3 encontrarás un resumen de los aspectos fundamentales del presente artículo así como un ejercicio que puedes empezar a aplicar de manera inmediata con tus jugadores.
3 Claves
- A mayor práctica, mayor efectividad.
- Practica primero contigo.
- Individualiza la práctica, diseña trajes a medida para tus jugadores.

\section{Ejercicio}
- Acostumbra a visualizar al comienzo del entrenamiento cómo serán las sensaciones una vez este termine.

Tabla 3. Claves prácticas de aplicación. 
Recordando las palabras de Einstein, "si buscas resultados distintos, no hagas siempre lo mismo". Ampliar el abanico de recursos como entrenador mediante visualizaciones sencillas, realistas y eficaces hará que los jugadores noten la diferencia y tú, como entrenador, también.

\section{REFERENCIAS}

Cox, R. H. (2009). Psicología del deporte: Conceptos y aplicaciones (6a ed.). Madrid: Editorial Panamericana.

Crespo, M., Reid, M., \& Quinn, A. (2006). Tennis Psychology. London: ITF Ltd.

Fernández-Abascal, E. G., Jiménez Sánchez, M. P., Martín Díaz, M. D., \& Domínguez Sánchez, F. J. (2010). Psicología de la emoción. Madrid: Editorial Universitaria Ramón Areces.

Fisher, A.C. (1986). Imagery from a sport psychology perspective. Paper presented at the meeting of the American Alliance for Health, Physical Education, Recreation and Dance, Cincinnati, Ohio.

Gallwey, T. (1997) El Juego Interior del tenis. Barcelona: Editorial Sirio.

Guillot, A., Desliens, S., Rouyer, C., \& Rogowski, I. (2013). Motor Imagery and Tennis Serve Performance: The External Focus Efficacy. Journal of Sports Science \& Medicine, 12(2), 332-338.

Mizuguchi, N., Yamagishi, T., Nakata, H., \& Kanosue, K. (2015). The effect of somatosensory input on motor imagery depends upon motor imagery capability. Frontiers in Psychology, 6, 104. https://doi.org/10.3389/fpsyg.2015.00104
Vealey, R. y Greenleaf, C. (2001). Seeing is believing: Understanding and using imagery in sport. En J. Williams (Ed.), Applied sport psychology. ( $\left.4^{\circ} \mathrm{Ed}\right)$. California: Mayfield Publishing Company.

CONTENIDO ITF ACADEMY RECOMENDADO (HAZCLICK ABAJO)

\section{ITF Academy}

Derechos de Autor (c) 2017 Lucía Jiménez.

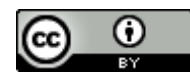

Este texto está protegido por una licencia CreativeCommons 4.0.

\footnotetext{
Usted es libre para Compartir -copiar y redistribuir el material en cualquier medio o formato- y Adaptar el documento - remezclar, transformar y crear a partir del material- para cualquier propósito, , incluso para fines comerciales, siempre que cumpla la condición de:

Atribución: Usted debe dar crédito a la obra original de manera adecuada, proporcionar un enlace a la licencia, e indicar si se han realizado cambios. Puede hacerlo en cualquier forma razonable, pero no de forma tal que sugiera que tiene

el apoyo del licenciante o lo recibe por el uso que hace de la obra. $\underline{\text { Resumendelicencia - Textocompletodelalicencia }}$
} 